\title{
APPENDIX
}

The preceding text comprises the article "Bubbles and Experience: An Experiment," which was accepted for publication in the American Economic Review in 2005. Space constraints forced us to omit many details from that article. This Appendix contains complementary material.

The appendix has three parts. Part A.I contains the experimental instructions. Part A.II reports more detailed results (the data is disaggregated for the 1/3- and 2/3experienced treatments, additional statistical tests are reported, more figures and tables are referred to, etc). Also included are avenues for further research. Part A.III reproduces figures and tables.

\section{A.I) INSTRUCTIONS}

\section{General instructions}

This is an experiment in the economics of market decision-making. The instructions are simple and if you follow them carefully and make good decisions, you might earn a considerable amount of money, which will be paid to you in cash at the end of the experiment. The experiment will consist of a sequence of trading periods in which you will have the opportunity to buy or sell in a market. All trading will be in terms of cents. Please do not speak with any other participants during this experiment. The experiment will last for approximately three hours, including one hour of instructions and practice.

\section{Market description:}

At the beginning of the market half of you will have an endowment of 6 goods (called X) and 200 cents and the other half will be endowed with 2 goods (called X) and 600 cents. 6 traders will participate in the market.

The market has 10 periods. In each period, you may buy or sell units of a good called X. $\mathrm{X}$ can be considered an asset with a life of 10 periods, and your inventory of $\mathrm{X}$ carries over from one trading period to the next. Each period lasts for 2 minutes.

At the end of each trading period, each unit of $\mathrm{X}$ pays a dividend. The dividend will be either 0 or 20 cents, which is randomly decided by the computer with a $50 \%$ chance of each dividend. Thus, the average dividend per period is 10 cents.

Your profits in the market will be equal to the total of the dividends that you receive on units of $\mathrm{X}$ in your inventory at the end of each of the market periods plus the cash you have at the end of the market. The way to calculate your earnings is described in section 3.

\section{Experimental procedure:}

The market, as described above, will be repeated four times. Before the first market starts, two (four) people in this room will be randomly selected and asked to leave the room for one hour. These people will not participate in the first three markets and they will not be doing anything connected with this experiment during these markets. In the 
fourth market they will replace two (four) randomly selected persons among the six that already have participated in three markets.

\section{Average Value Holding Table}

You can use the table in section 4 to help you make decisions. There are 5 columns in the table. The first column, labeled Ending Period, indicates the last trading period of the market. The second column, labeled Current Period, indicates the period during which the average holding value is being calculated. The third column gives the number of holding periods from the period in the second column until the end of the market. The fourth column, labeled Average Dividend Value Per Period, gives the average amount that the dividend will be in each period for each unit held in your inventory. The fifth column, labeled Average Holding Value Per Unit of Inventory, gives the expected total dividend for the remainder of the experiment for each unit held in your inventory for the rest of the market. That is, for each unit you hold in your inventory for the remainder of the market, you receive in expectation the amount listed in column 5. The number in column 5 is calculated by multiplying the numbers in columns 3 and 4 .

Suppose for example that there are 4 periods remaining. Since the dividend paid on a unit of $\mathrm{X}$ has a $50 \%$ chance of being 0 and a $50 \%$ chance of being 20 , the dividend is in expectation 10 per period for each unit of X. If you hold a unit of $\mathrm{X}$ for 4 periods, the total dividend paid on the unit over the 4 periods is in expectation $4 \times 10=40$.

\section{Calculate Your Earnings}

Your earnings in each period equal the value of the dividends you receive at the end of the period for the units of $\mathrm{X}$ in your inventory at the end of the period. That is, YOUR EARNINGS FOR A PERIOD =

DIVIDEND PER UNIT $\times$ NUMBER OF UNITS IN INVENTORY AT THE END OF PERIOD.

However, when you spend money to buy units of $\mathrm{X}$, the total amount of cash that you have after period 10 is reduced by the amount of the purchase. If you sell units of $X$, the total amount of cash you have after period 10 increases by the amount of the sale. Your total earnings for one market are the total of your earnings for periods 1-10 plus the amount of cash that you have at the end of period 10. That is

YOUR TOTAL EARNINGS IN THE MARKET $=$

EARNINGS FOR PERIOD $1+$ EARNINGS FOR PERIOD $2+$ EARNINGS FOR PERIOD $3+$ EARNINGS FOR PERIOD 4 + EARNINGS FOR PERIOD 5 + EARNINGS FOR PERIOD $6+$ EARNINGS FOR PERIOD 7 + EARNINGS FOR PERIOD 8 + EARNINGS FOR PERIOD $9+$ EARNINGS FOR PERIOD 10 + CASH ON HAND AT THE END OF PERIOD 10.

Your profit for the entire experiment is the sum of the profits from all of the markets that you participate in. Note that you do not have to calculate your profit by yourself. The computer does all the work.

There will also be a show up fee of $\$ 5$ to all participants. The two people that have to leave for one hour will receive an extra $\$ 10$ each (plus the $\$ 5$ ). 


\section{Average Value Holding Table}

$\begin{array}{ccccc}\begin{array}{l}\text { Ending } \\ \text { Period }\end{array} & \begin{array}{c}\text { Current } \\ \text { Period }\end{array} & \begin{array}{c}\text { Number of } \\ \text { Holding Periods }\end{array} & \begin{array}{c}\text { Average Dividend } \\ \times \text { Value Per Period }\end{array} & \begin{array}{c}\text { Average Holding Value } \\ \text { Per Unit of Inventory }\end{array} \\ 10 & 1 & 10 & 10 & 100 \\ 10 & 2 & 9 & 10 & 90 \\ 10 & 3 & 8 & 10 & 80 \\ 10 & 4 & 7 & 10 & 70 \\ 10 & 5 & 6 & 10 & 60 \\ 10 & 6 & 5 & 10 & 50 \\ 10 & 7 & 4 & 10 & 40 \\ 10 & 8 & 3 & 10 & 30 \\ 10 & 9 & 2 & 10 & 20 \\ 10 & 10 & 1 & 10 & 10\end{array}$

\section{Information about the screen}

Remaining time (sec) This shows the time remaining in the period in seconds. Each period lasts two minutes so the timer counts down from 120 seconds to 0 seconds.

Period This shows the number of the period you are in for each market. There are 10 periods in each market.

Cents The number of cents that you have.

Units of good X The number of units of good X that you have.

\section{Buttons at the bottom of the screen}

Sales ask Type the amount, in cents, that you are willing to sell a unit of good X for in the box marked "Sales ask". Then press the "Sales ask" button at the bottom of the screen to offer the unit for sale.

Purchase bid Type the amount, in cents, that you are willing to pay for a unit of good X in the box marked "Purchase bid". Then press the

"Purchase bid" button at the bottom of the screen to place your bid.

Sell Press the "Sell" button if you would like to sell a unit of good X for the highlighted amount in the "Purchase bid" column. 
Buy Press the "Buy" button if you would like to buy a unit of good X for the highlighted amount in the "Sales ask" column.

\section{Columns in the middle of the screen}

Sales ask column

Transaction price column

Purchase bid column

Shows all of the available "Sales asks" in descending order so that the lowest price is at the bottom.

Shows all of the prices at which a unit of good $\mathrm{X}$ has been bought or sold in the current period.

Shows all of the available "Purchase bids" in ascending order so that the highest price is at the bottom.

\section{Earnings Report}

The earnings report appears at the end of each period. After seeing your earnings, press the "Continue" button to go to the next period. The next period will begin once all of you press the "Continue" button. 


\section{A.II) ADDITIONAL RESULTS}

To facilitate overview, the following list presents the contents of section A.II:
A. Prices by sessions and related statistical tests
B. Pricing in the $2 / 3$-EXPERIENCED treatment
C. Pricing in the $1 / 3$-EXPERIENCED treatment
D. Excess bids and price changes
E. Correlations of average prices between rounds
F. Additional results [on turnover, market openings, and earnings differences]
G. Further research

All figures and tables referred to below appear in section A.III.

\section{A. Prices by sessions and related statistical tests}

Figure 1A plots mean trading prices and fundamental values for each session. Sessions 1-5 [6-10] correspond with the $2 / 3$ [1/3]-EXPERIENCED treatment. The session numbers, matching those provided in Table 1, are also provided. Table 1A, which follows, provides summary values of the statistics provided in Table 1 for each round.

[Figure 1A here]

[Table 1A here]

\section{B. Pricing in the $2 / 3$-EXPERIENCED treatment}

Our main interest is to examine differences between rounds 1 and 4, comparing how well trading prices conform to fundamental values in inexperienced and mixed-experience markets. Using Table 1A, observe that the goodness-of-fit increases in all but the first session. ${ }^{1}$ Overall, we can reject the null hypothesis of a similar fit in the two rounds at marginal significance levels $(p=0.063)$; a market with a two-thirds majority of experienced traders is trading closer to fundamental values than a market where every 
trader is inexperienced. Similarly, the normalized absolute and average price deviations, and the price amplitude, are all statistically significantly $(p=0.031)$ lower than in the first round.

A comparison of round 4 prices to round 3 prices allows one to judge if trading in a mixed-experience market is similar to that in a market with experienced traders. Recall that the received wisdom is that bubbles virtually vanish by the third time a market is repeated. We find that the entry of the inexperienced traders in round 4 does not affect prices relative to the outcome in round 3. The null hypothesis of a similar goodness-of-fit in rounds 3 and 4 (against the alternative hypothesis of a better fit in round 3) cannot be rejected $(p=0.719)$. With two-thirds experienced traders, prices are as close to the fundamental price as in a thrice-repeated market (i.e., a market consisting solely of traders with considerable experience). Note that none of the other pricing statistics are significantly different between these rounds.

Main result in the 2/3-EXPERIENCED treatment: Bubble-crash pricing phenomena do not occur in a market containing a majority of experienced subjects.

\section{Pricing in the $1 / 3$-EXPERIENCED treatment}

We next report on our second treatment where, in round 4, we mix four inexperienced with two experienced traders.

Again using Table 1A, the goodness-of-fit increases in all but the third session. Just as before, we can reject the null hypothesis of a similar fit between rounds 1 and 4 at marginal significance levels $(p=0.063)$. A market with a minority of experienced traders is also trading closer to fundamental values than a market without experienced traders. The other measures are lower, as expected, in round 4. However, this difference is not statistically significantly for either price deviation. The price amplitude is statistically marginally lower $(\mathrm{p}=0.063)$.

\footnotetext{
${ }^{1}$ In session 1, the Haessel- $\mathrm{R}^{2}$ starts and ends very low. Prices actually increase across the ten periods, a pattern opposite to the fundamental. We suspect some subjects in this session did not understand the market.
} 
And as for mixed-experience markets versus experienced, we again evaluate this by comparing round 4 prices to round 3 prices. We find that the entry of the inexperienced traders in round 4 does not affect prices relative to the outcome in round 3 . The null hypothesis of a similar goodness-of-fit in rounds 3 and 4 (against the alternative hypothesis of a better fit in round 3) cannot be rejected $(p=0.281)$. The normalized average price deviation and price amplitude are not significantly different, while the difference in normalized absolute price deviation is marginally significant at the 10 percent level.

Main result in the 1/3-EXPERIENCED treatment: Bubble-crash pricing phenomena do not occur in a market containing a minority of experienced subjects.

\section{Excess bids and price changes}

Earlier experiments have observed a positive relationship between prices and the number of offers to buy and sell (e.g. Smith, Suchanek \& Williams, 1988; Lei, Noussair \& Plott, 2001). The equation used to test for this is

$$
P_{t}-P_{t-1}=a+b\left(B_{t-1}-O_{t-1}\right)
$$

where $P_{t}$ and $P_{t-1}$ are the average transaction prices in period $t$ and $t-1$ respectively, $B_{t-1}$ is the total number of offers to buy, and $O_{t-1}$ is the total number of asks to sell in period $t$ 1. Theoretically $a$ is -10 and $b$ is zero since the price should not be reflected in demands in the previous period.

Table 2A presents the results from regression analyses for all rounds for each treatment.

[Insert Table 2A here]

The coefficient $a$ is significantly different from -10 in 7 of the 10 sessions in round 1 and 6 of the 10 sessions in round 2. The coefficient $b$ is positive in 7 of the 10 sessions in round 1. Positive $b$ values are usually indicative of a price bubble. However, the 
coefficient is significantly different from zero $(p$-value $<0.05)$ in only one of these cases. The coefficient $b$ is positive in 6 of the 10 sessions in round 2 , with 3 of these values significantly different from zero ( $p$-value $<0.01$ and $p$-value $<0.05$ ).

Both coefficients do not essentially diverge from round 3 to 4 in either treatment. The coefficient $a$ is significantly different from -10 in 4 of the 10 sessions in round 3 and 5 of the 10 sessions in round 4 . These estimates are in line with former results indicating that the market price does not fully reflect fundamental values. The coefficient $b$ is positive in 7 and 5 of the 10 sessions in rounds 3 and 4 respectively. It is significantly different from zero ( $p$-value $<0.05$ ) in only 1 of the 10 sessions in each of rounds 3 and 4 respectively. This suggests that changes in prices between periods do not appear to be driven by excess demand or supply conditions, which is a typical finding when bubbles are present.

\section{E. Correlations of Average Prices Between Rounds}

Table $3 \mathrm{~A}$ presents correlations of average trading prices between rounds by session.

[Insert Table 3A here]

The high correlation between average prices in rounds 3 and 4 in both treatments is not surprising given our earlier findings. There is some disparity between the average correlations of rounds 1 and 4 between the treatments ( -0.03 vs 0.40$)$. Both values are considerably less than 1 . Looking at results from other measures, this disparity has more to do with the seemingly somewhat random trading in round 1 rather than with differences between round 4 in each of the treatments.

\section{F. Additional results}

So far we have only looked at market prices, but other characteristics of the market may differ between rounds. In this section we report results regarding turnover, market openings, and earnings differences.

\section{$\underline{\text { Turnover }}$}


Our findings on pricing suggest that there is no considerable difference between mixedexperience markets (round 4) and markets where all of the traders are experienced (round 3). However, we find significant differences between the mixed-experience markets and markets where all of the traders are inexperienced (round 1). Do analogous results carry over to turnover? Turnover is the volume of trades divided by the total number of outstanding assets, i.e. the total number of trades divided by 24 for each round. Table $4 \mathrm{~A}$ gives details for each of our ten sessions.

\section{[Insert Table 4A here]}

In both treatments the turnover falls as subjects gain experience in rounds 1 through 3 . However, with the introduction of inexperienced players in round 4 the turnover increases above the levels in round 3. The marginally significant differences ( $p$-values of 0.063 and 0.094 for the individual treatments and 0.079 when the treatments are pooled) in turnover suggest that the level of market activity does increase.

Result on Turnover: The turnover in mixed-experience markets is marginally significantly greater than in markets where all traders are relatively experienced.

This result made us curious. Is it the experienced or the inexperienced traders who are responsible for the increased trade in round 4 ? Table $5 \mathrm{~A}$ reports the number of trades between traders by experience level. For example, in session 1 of the $2 / 3$ experienced treatment, there are 4 trades between inexperienced subjects. The data reported in this table shows that both categories have similar trade volumes. It seems like the experienced traders tried to exploit the inexperienced traders, and that in this process the trading volume increased. ${ }^{2}$

[Insert Table 5A here]

\footnotetext{
2 This motivation was mentioned by many subjects during the debriefing after the experiment.
} 


\section{Market Openings}

Who takes the initiative in the mixed-experience markets? That is, who is first to enter the market and propose a trade? To answer this question we look into the data in round 4, where traders have mixed experience, for all of the sessions. In the beginning of round 4 of each session, i.e. the first seconds of period 1, we observe who first offers a bid or makes an ask (not necessary implying a trade). These 'market openings' are made visible on the screen for all traders.

It turns out that no inexperienced trader was ever the first to enter in period 1 , in any of the ten sessions. In the $2 / 3$-EXPERIENCED we did not observe any inexperienced trader as second enterer either.

In the $1 / 3$-EXPERIENCED treatment two of the six traders are experienced. Assuming random entering, the probability that all traders first entering period 1 are experienced in all of the five sessions of this treatment is $(2 / 6)^{5}$, which is less than 0.005 . The corresponding probability that all first and second traders are experienced is 0.017 $\left(\approx(4 / 6)^{10}\right)$ in the $2 / 3$-EXPERIENCED treatment. We conclude that random entering can be rejected in both treatments.

Result on Market Openings: Experienced traders always open the market.

\section{Earnings Differences}

Do differences in experience generate differences in earnings? One may suspect that in a mixed-experience market the experienced traders somehow manage to take advantage of the inexperienced traders that just entered. We begin our test of this conjecture by summarizing the average fourth round earnings in Table $6 \mathrm{~A}$.

[Insert Table 6A here]

The average expected earning per round is $\$ 8$ (by design), but the realized earnings may deviate from $\$ 8$ depending on dividend realizations. As seen in Table 6A, on average experienced traders earned more, and inexperienced traders less, than $\$ 8$. In the $2 / 3-$ 
EXPERIENCED treatment, 3 out of 10 inexperienced traders and 13 out of 20 experienced traders earned above $\$ 8$. In the $1 / 3$-EXPERIENCED treatment, 6 out of 20 inexperienced traders vs 7 out of 10 experienced traders earned above the expected average. ${ }^{3}$

Statistical tests confirm that this picture is systematic. We use unpaired $t$-tests to examine the hypothesis that mean earnings are the same for each trader category, and reject the hypothesis for each treatment $(p=0.048$ in the $2 / 3$-EXPERIENCED treatment; $p=0.075$ in the $1 / 3$-EXPERIENCED treatment).

Tables 7A and 8A presents earnings differences for the two treatments in more detail.

[Insert Table 7A here]

[Insert Table 8A here]

In the $2 / 3$-EXPERIENCED treatment we have a total of 10 inexperienced subjects and 20 experienced subjects participating in the $4^{\text {th }}$ round. The inexperienced (experienced) subjects start with a total of 40 assets (80 assets) and $\$ 40(\$ 80)$. The initial conditions are reversed in the $1 / 3$-EXPERIENCED treatment. The driving factor in the earnings differences can be seen in the net trading columns. Note that the inexperienced subjects trade for net losses in the majority of the periods in both treatments. Furthermore, much of this loss occurs due to paying higher average prices while selling for lower average prices during the early rounds.

Result on Earnings: Experienced traders earn more, on average, than inexperienced traders.

\section{G. Further Research}

Out of the possible suggestions for future research, let us mention three: First, inexperience may relate to other things than market participation. What is the effect, for example, of changing the stochastic dividend structure after a few rounds? Second, most

\footnotetext{
3 An additional inexperienced subject earned exactly $\$ 8.00$ in the 1/3-EXPERIENCED treatment.
} 
markets outside the laboratory do not have an exogenously given duration. Examining markets with a stochastically determined last period may be interesting. Third, in our design all participants knew when and how many inexperienced participants entered the markets. It may be realistic to consider alternative designs where this information is not given. 


\section{A.III) FIGURES \& TABLES}

FIGURE 1A. OBSERVED MEAN PRICES RELATIVE TO FUNDAMENTAL VALUE.
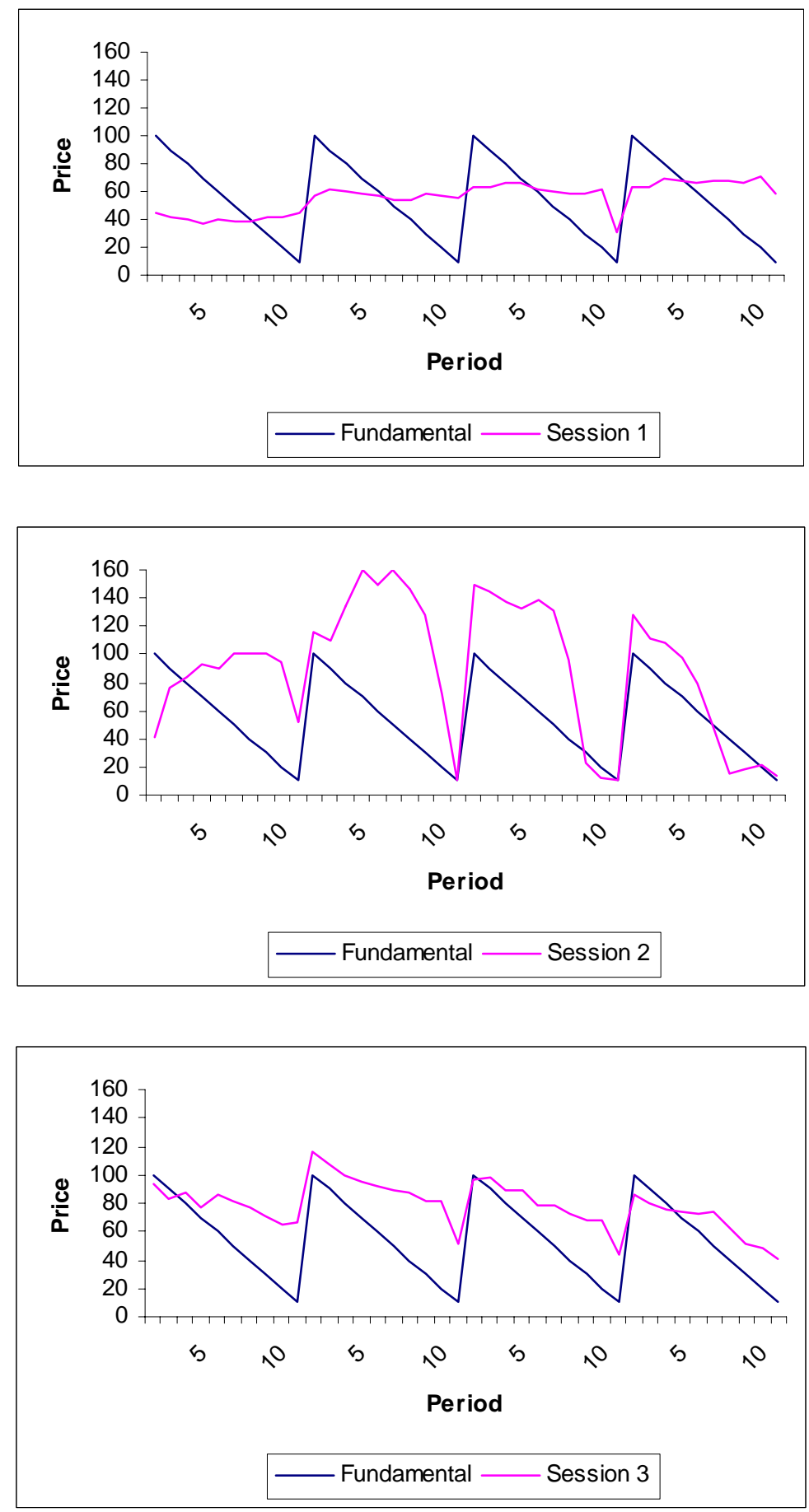


\section{...FIGURE 1A (continued)}
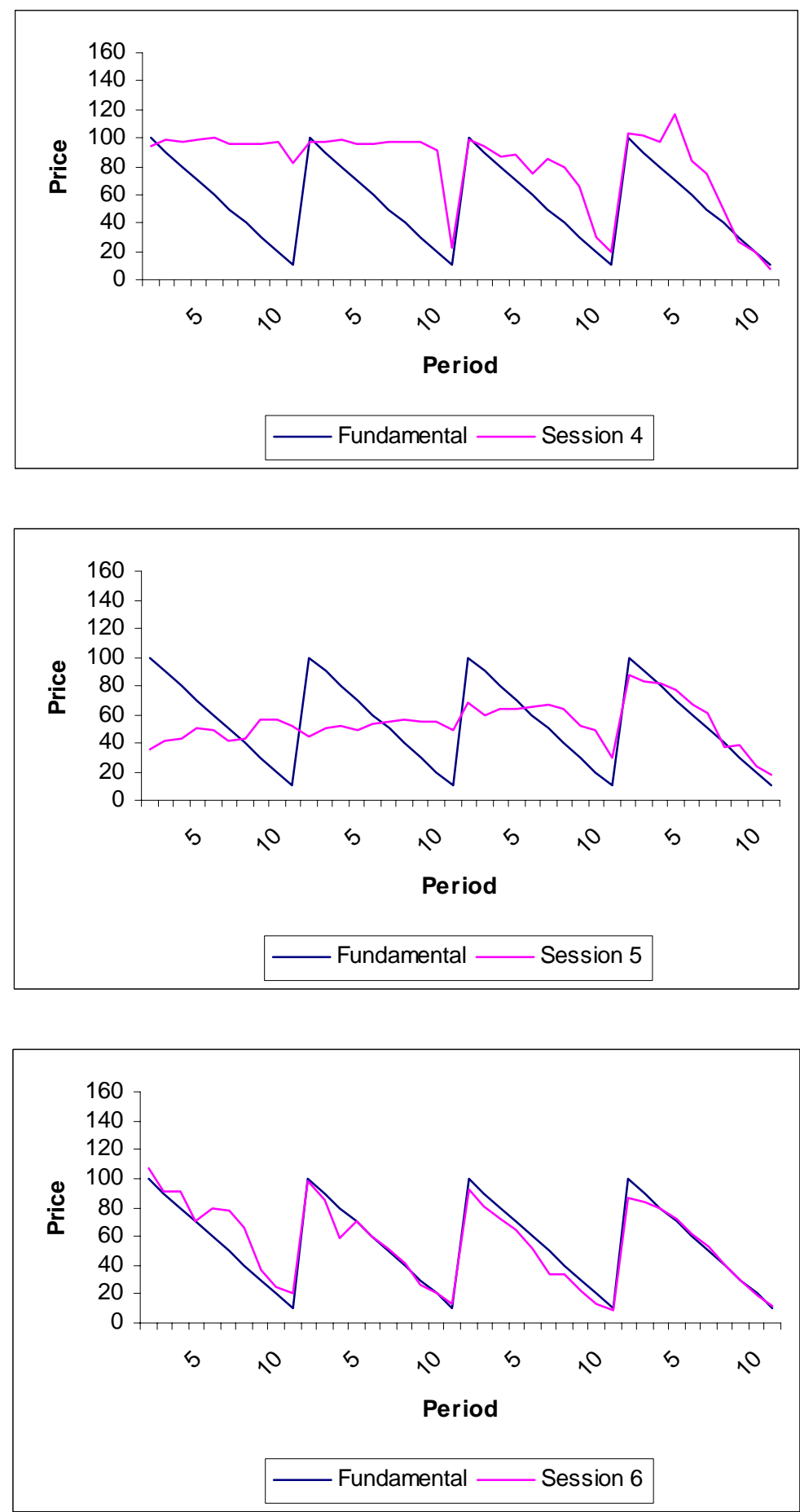


\section{...FIGURE 1A (continued)}
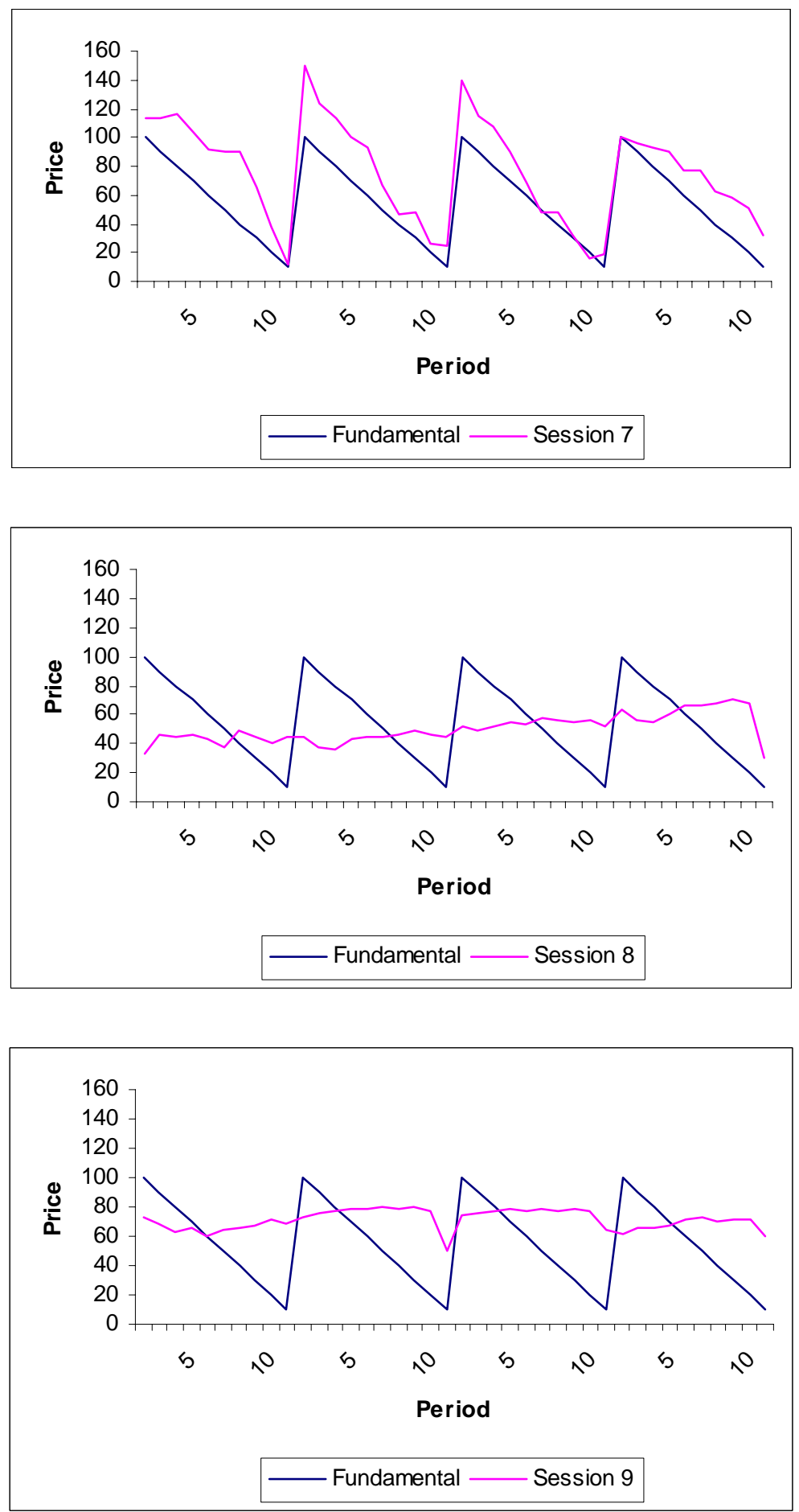
...FIGURE 1A (continued)

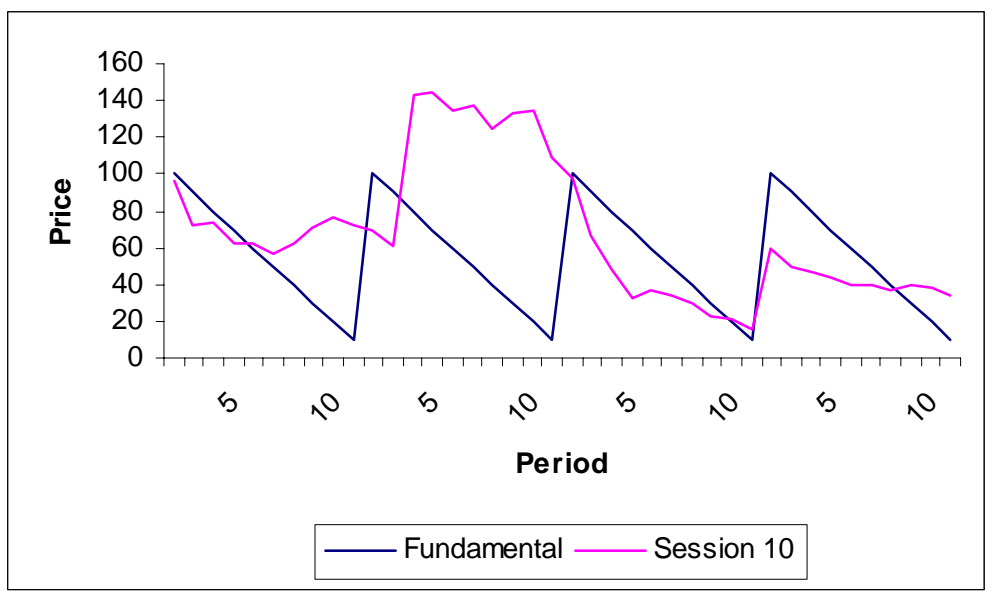


TABLE 1A-SUMMARY STATISTICS

\begin{tabular}{|c|c|c|c|c|c|}
\hline Treatment & Round (R) & $\begin{array}{c}\text { Haessel- } \\
R^{2}\end{array}$ & $\begin{array}{c}\text { Normalized } \\
\text { Absolute } \\
\text { Price } \\
\text { Deviation }\end{array}$ & $\begin{array}{c}\text { Normalized } \\
\text { Average } \\
\text { Price } \\
\text { Deviation } \\
\end{array}$ & $\begin{array}{c}\text { Price } \\
\text { Amplitude }\end{array}$ \\
\hline \multirow{6}{*}{$\begin{array}{c}2 / 3- \\
\text { EXPERIENCED }\end{array}$} & 1 & 0.35 & 1.85 & 0.14 & 0.95 \\
\hline & 2 & 0.40 & 1.71 & 0.15 & 0.82 \\
\hline & 3 & 0.65 & 0.89 & 0.11 & 0.64 \\
\hline & 4 & 0.73 & 0.87 & 0.07 & 0.52 \\
\hline & $p$-value $\mathrm{R} 1=\mathrm{R} 4^{a}$ & $0.063^{*}$ & $0.031 * *$ & $0.031 * *$ & $0.031 * *$ \\
\hline & $p$-value $\mathrm{R} 3=\mathrm{R} 4^{b}$ & 0.719 & 0.500 & 0.938 & 0.813 \\
\hline \multirow{7}{*}{$\begin{array}{c}1 / 3- \\
\text { EXPERIENCED }\end{array}$} & 1 & 0.38 & 1.48 & 0.10 & 0.68 \\
\hline & 2 & 0.53 & 1.52 & 0.13 & 0.77 \\
\hline & 3 & 0.63 & 0.74 & 0.08 & 0.55 \\
\hline & 4 & 0.57 & 1.26 & 0.08 & 0.58 \\
\hline & $p$-value $\mathrm{R} 1=\mathrm{R} 4^{a}$ & $0.063 *$ & 0.281 & 0.156 & $0.063^{*}$ \\
\hline & $p$-value $\mathrm{R} 2=\mathrm{R} 4^{c}$ & 0.656 & 0.656 & 0.906 & 0.875 \\
\hline & $p$-value $\mathrm{R} 3=\mathrm{R} 4^{b}$ & 0.281 & $0.094 *$ & 0.281 & 0.344 \\
\hline BETWEEN & $p$-value $\mathrm{R} 4-{ }^{2} / 3=\mathrm{R} 4-{ }^{1} 3^{d}$ & 1.000 & 0.421 & 0.310 & 0.841 \\
\hline \multirow{6}{*}{ POOLED DATA } & 1 & 0.37 & 1.67 & 0.12 & 0.81 \\
\hline & 2 & 0.47 & 1.61 & 0.14 & 0.80 \\
\hline & 3 & 0.64 & 0.81 & 0.09 & 0.59 \\
\hline & 4 & 0.65 & 1.06 & 0.08 & 0.55 \\
\hline & $p$-value $\mathrm{R} 1=\mathrm{R} 4^{a}$ & $0.004 * * *$ & $0.032 * *$ & $0.011^{* *}$ & $0.003 * * *$ \\
\hline & $p$-value $\mathrm{R} 3=\mathrm{R} 4^{b}$ & 0.618 & $0.061 *$ & 0.897 & 0.819 \\
\hline
\end{tabular}

${ }^{a}$ Null hypothesis: R1=R4 (meaning, round 1 measure equals round 4 measure); alternative hypothesis: $\mathrm{R} 1<\mathrm{R} 4$ for Haessel- $R^{2}$ and $\mathrm{R} 1>\mathrm{R} 4$ for the other measures

${ }^{b}$ Null hypothesis: R3=R4; alternative hypothesis: R3 $>\mathrm{R} 4$ for Haessel- $R^{2}, \mathrm{R} 3<\mathrm{R} 4$ for the other measures

${ }^{c}$ Null hypothesis: R2=R4; alternative hypothesis: R2 $>\mathrm{R} 4$ for Haessel- $R^{2}, \mathrm{R} 2<\mathrm{R} 4$ for the other measures. A comparison between round 2 and 4 in this treatment tests the effect of the variability of experience levels between market participants, while holding the average level of experience constant. In round 4 the average trader has one round of experience ( $1 / 3$ have three rounds and $2 / 3$ have none). In round 2 all traders have exactly one round of previous experience. In the same spirit, round 3 and 4 in the $2 / 3$-EXPERIENCED treatment can be compared. As the $p$-values in the table indicate, no differences are observed (as does not the $p$-value $=0.156$ for Turnover for $\mathrm{R} 2=\mathrm{R} 4$, see more in Table $4 \mathrm{~A})$

${ }^{d}$ Wilcoxon-Mann-Whitney test with null hypothesis $\mathrm{R} 4-{ }^{2} / 3=\mathrm{R} 4-1 / 3$ (meaning, equal round 4 measure for sessions with $2 / 3$ and $1 / 3$ experienced traders); alternative hypothesis R $4-2 / 3 \neq R 4-1 / 3$ (cf. Table 1 )

* Significant at $10 \%$ level; ** Significant at 5\% level; *** Significant at 1\% level 
TABle 2A-Number of OfFers AND EFFECT ON Price Changes

\begin{tabular}{|c|c|c|c|c|c|c|c|c|c|c|c|c|c|}
\hline \multicolumn{14}{|c|}{$2 / 3$-EXPERIENCED } \\
\hline ROUND & 1 & & & & & & ROUND & 2 & & & & & \\
\hline session & $\mathrm{a}$ & & t-stat & $\mathrm{b}$ & & t-stat & session & $\mathrm{a}$ & & t-stat & $\mathrm{b}$ & & t-stat \\
\hline 1 & 0.507 & $* * *$ & $(9.46)$ & 0.086 & & $(0.85)$ & 1 & -0.245 & $* * *$ & $(-9.04)$ & 0.017 & & $(0.25)$ \\
\hline 2 & 5.342 & & $(1.60)$ & 0.555 & & $(0.65)$ & 2 & 7.573 & $*$ & $(2.06)$ & 2.270 & $* * *$ & $(3.54)$ \\
\hline 3 & -3.906 & $* *$ & $(-2.80)$ & -0.457 & & $(-1.38)$ & 3 & -11.116 & & $(-0.24)$ & -1.392 & & $(-1.21)$ \\
\hline 4 & 0.383 & $* * *$ & $(4.78)$ & 0.660 & & $(1.39)$ & 4 & -5.666 & & $(-0.57)$ & 1.200 & & $(1.24)$ \\
\hline 5 & 5.226 & $* * *$ & $(5.08)$ & 0.346 & & $(1.55)$ & 5 & 1.579 & $* * *$ & $(8.09)$ & -0.389 & & $(-1.28)$ \\
\hline ROUND & 3 & & & & & & ROUND & 4 & & & & & \\
\hline session & $\mathrm{a}$ & & t-stat & $\mathrm{b}$ & & t-stat & session & $\mathrm{a}$ & & t-stat & $\mathrm{b}$ & & t-stat \\
\hline 1 & -3.642 & & $(-0.77)$ & 0.407 & & $(0.65)$ & 1 & -1.732 & $* * *$ & $(-3.70)$ & -0.227 & & $(-1.00)$ \\
\hline 2 & -9.374 & & $(-0.10)$ & 1.534 & & $(1.60)$ & 2 & -10.116 & & $(-0.00)$ & 0.629 & & $(1.17)$ \\
\hline 3 & -6.094 & & $(-1.42)$ & 0.325 & & $(0.56)$ & 3 & -4.974 & $* * *$ & $(-3.80)$ & 0.405 & & $(1.52)$ \\
\hline 4 & -7.507 & & $(-0.54)$ & 0.212 & & $(0.84)$ & 4 & -4.534 & & $(-1.08)$ & 1.278 & $*$ & $(2.20)$ \\
\hline 5 & -4.784 & $* *$ & $(-2.54)$ & 0.590 & $*$ & $(2.27)$ & 5 & -8.379 & & $(-0.40)$ & -0.110 & & $(-0.18)$ \\
\hline \multicolumn{14}{|c|}{ 1/3-EXPERIENCED } \\
\hline ROUND & 1 & & & & & & ROUND & 2 & & & & & \\
\hline session & $\mathrm{a}$ & & t-stat & $\mathrm{b}$ & & t-stat & session & $\mathrm{a}$ & & t-stat & $\mathrm{b}$ & & t-stat \\
\hline 6 & -11.108 & & $(-0.17)$ & -0.247 & & $(-0.31)$ & 6 & 1.469 & $* *$ & $(2.57)$ & 1.164 & $* *$ & $(2.89)$ \\
\hline 7 & -15.407 & & $(-0.84)$ & -1.052 & & $(-0.86)$ & 7 & -22.706 & & $(-1.67)$ & -1.368 & & $(-1.29)$ \\
\hline 8 & 1.799 & $* * *$ & $(3.55)$ & 0.090 & & $(0.23)$ & 8 & 0.366 & $* * *$ & $(5.87)$ & 0.132 & & $(0.32)$ \\
\hline 9 & 0.236 & $* * *$ & (7.23) & 0.114 & & (1.44) & 9 & -2.468 & $* * *$ & $(-4.18)$ & 0.622 & $* * *$ & (3.94) \\
\hline 10 & 4.299 & $* * *$ & (3.65) & 0.739 & $* *$ & $(2.43)$ & 10 & -10.444 & & $(-0.00)$ & -0.978 & & $(-0.65)$ \\
\hline ROUND & 3 & & & & & & ROUND & 4 & & & & & \\
\hline session & $\mathrm{a}$ & & t-stat & $\mathrm{b}$ & & t-stat & session & $\mathrm{a}$ & & t-stat & $\mathrm{b}$ & & t-stat \\
\hline 6 & -5.548 & $* *$ & $(-2.80)$ & 0.591 & $* *$ & $(3.23)$ & 6 & -11.039 & & $(-0.61)$ & -0.222 & $*$ & $(-2.00)$ \\
\hline 7 & -16.377 & & $(-1.37)$ & -0.986 & & $(-0.90)$ & 7 & -7.909 & & $(-0.67)$ & -0.094 & & $(-0.17)$ \\
\hline 8 & -0.458 & $* * *$ & $(-9.80)$ & -0.163 & & $(-1.12)$ & 8 & -2.806 & $* *$ & $(-3.18)$ & 0.735 & $* * *$ & (4.94) \\
\hline 9 & 0.466 & $* * *$ & $(4.84)$ & 0.281 & & $(1.04)$ & 9 & 1.884 & $* * *$ & $(5.06)$ & 0.445 & & (1.13) \\
\hline 10 & -18.851 & & $(-1.01)$ & -0.239 & & $(-1.21)$ & 10 & -3.471 & $* * *$ & $(-4.67)$ & -0.153 & & $(-0.85)$ \\
\hline
\end{tabular}

* Significant at $10 \%$ level; ** Significant at $5 \%$ level; *** Significant at $1 \%$ level 
TABle 3A-CORRelations of AVERAge Prices BetweEn Rounds

\begin{tabular}{ccccc}
\hline \hline $\begin{array}{c}\text { 2/3-EXPERIENCED } \\
\text { Session }\end{array}$ & R1 and R2 & R2 and R3 & R3 and R4 & R1 and R4 \\
\hline 1 & 0.17 & 0.26 & 0.51 & -0.62 \\
2 & 0.58 & 0.68 & 0.84 & -0.38 \\
3 & 0.84 & 0.98 & 0.93 & 0.93 \\
4 & 0.91 & 0.74 & 0.88 & 0.61 \\
5 & 0.43 & 0.07 & 0.76 & -0.69 \\
Average & 0.59 & 0.55 & 0.79 & -0.03 \\
& & & & \\
$1 / 3$-EXPERIENCED & & & & \\
Session & R1 and R2 & R2 and R3 & R3 and R4 & R1 and R4 \\
6 & 0.93 & 0.96 & 0.98 & 0.95 \\
7 & 0.86 & 0.99 & 0.93 & 0.95 \\
8 & -0.16 & 0.72 & 0.49 & -0.17 \\
9 & -0.27 & 0.99 & 0.72 & -0.41 \\
10 & -0.60 & -0.73 & 0.96 & 0.70 \\
Average & 0.15 & 0.58 & 0.82 & 0.40 \\
\hline
\end{tabular}


TABLE 4A-TURNOVER

\begin{tabular}{|c|c|c|c|c|c|c|c|c|c|c|c|c|c|}
\hline & \multicolumn{5}{|c|}{ 2/3-EXPERIENCED } & \multicolumn{7}{|c|}{ 1/3- EXPERIENCED } & \multirow{2}{*}{$\begin{array}{c}\text { POOLED } \\
\text { DATA }\end{array}$} \\
\hline & 1 & 2 & 3 & 4 & 5 & Average & 6 & 7 & 8 & 9 & 10 & Average & \\
\hline R1 & 7.08 & 3.88 & 5.00 & 4.46 & 5.54 & 5.19 & 3.08 & 3.42 & 7.71 & 6.46 & 7.13 & 5.56 & 5.38 \\
\hline $\mathrm{R} 2$ & 7.88 & 2.83 & 7.04 & 2.75 & 4.38 & 4.98 & 2.63 & 2.00 & 5.17 & 3.75 & 5.50 & 3.81 & 4.39 \\
\hline $\mathrm{R} 3$ & 5.42 & 1.96 & 5.71 & 2.67 & 2.08 & 3.57 & 2.54 & 1.88 & 5.71 & 2.63 & 5.21 & 3.59 & 3.58 \\
\hline $\mathrm{R} 4$ & 6.75 & 3.42 & 6.88 & 1.25 & 3.38 & 4.33 & 3.63 & 6.29 & 3.54 & 4.25 & 10.33 & 5.61 & 4.97 \\
\hline \multicolumn{6}{|c|}{$p$-value $\mathrm{R} 1=\mathrm{R} 4^{a}$} & 0.156 & & & & & & 0.438 & 0.325 \\
\hline \multicolumn{6}{|c|}{$p$-value $\mathrm{R} 3=\mathrm{R} 4^{b}$} & $0.063 *$ & & & & & & $0.094 *$ & $0.079 *$ \\
\hline \multicolumn{6}{|c|}{$p$-value $\mathrm{R} 4-2 / 3=\mathrm{R} 4-1 / 3^{c}$} & & & & & & & & 0.421 \\
\hline
\end{tabular}

${ }^{a}$ Null hypothesis: R1=R4 (meaning, round 1 measure equals round 4 measure); alternative hypothesis: $\mathrm{R} 1>\mathrm{R} 4$

${ }^{b}$ Null hypothesis: R3=R4; alternative hypothesis: R3 $<\mathrm{R} 4$

${ }^{c}$ Wilcoxon-Mann-Whitney test with null hypothesis $\mathrm{R} 4-2 / 3=\mathrm{R} 4-1 / 3$ (meaning, equal round 4 measure for sessions with $2 / 3$ and $1 / 3$ experienced traders); alternative hypothesis $\mathrm{R} 4-2 / 3 \neq \mathrm{R} 4-1 / 3$

* Significant at $10 \%$ level; ** Significant at $5 \%$ level; *** Significant at $1 \%$ level 
TABLE 5A-TRADE VOLUME IN ROUND 4

\begin{tabular}{|c|c|c|c|c|c|c|}
\hline \multicolumn{7}{|l|}{ 2/3-EXPERIENCED } \\
\hline Session & Inexp vs Inexp & Inexp vs Exp & Exp vs Exp & $\begin{array}{l}\text { Exp average } \\
\text { trade volume }\end{array}$ & $\begin{array}{l}\text { Inexp average } \\
\text { trade volume }\end{array}$ & $\begin{array}{c}p \text {-value } \\
\text { Inexp=Exp }\end{array}$ \\
\hline 1 & 4 & 61 & 97 & 34.50 & 63.75 & \\
\hline 2 & 6 & 57 & 19 & 34.50 & 23.75 & \\
\hline 3 & 7 & 93 & 65 & 53.50 & 55.75 & \\
\hline 4 & 0 & 18 & 12 & 9.00 & 10.50 & \\
\hline 5 & 8 & 41 & 32 & 28.50 & 26.25 & \\
\hline Average & & & & 32.00 & 36.00 & 0.750 \\
\hline \multicolumn{7}{|l|}{ 1/3-EXPERIENCED } \\
\hline Session & Inexp vs Inexp & Inexp vs Exp & Exp vs Exp & $\begin{array}{l}\text { Exp average } \\
\text { trade volume }\end{array}$ & $\begin{array}{l}\text { Inexp average } \\
\text { trade volume }\end{array}$ & $\begin{array}{c}p \text {-value } \\
\text { Inexp=Exp }\end{array}$ \\
\hline 6 & 37 & 46 & 4 & 30 & 27.00 & \\
\hline 7 & 33 & 108 & 10 & 43.50 & 64.00 & \\
\hline 8 & 52 & 31 & 3 & 33.75 & 18.50 & \\
\hline 9 & 60 & 42 & 0 & 40.50 & 21.00 & \\
\hline 10 & 137 & 105 & 6 & 94.75 & 58.50 & \\
\hline Average & & & & 48.50 & 37.80 & 0.563 \\
\hline Average pooled & & & & 43.00 & 36.60 & 0.760 \\
\hline
\end{tabular}

a Null hypothesis Inexp=Exp (meaning, trade volume by inexperienced equals trade volume by experienced); alternative hypothesis: Inexp $\neq$ Exp

* Significant at $10 \%$ level; ** Significant at $5 \%$ level; *** Significant at $1 \%$ level 
TABLE 6A-EARNINGS

\begin{tabular}{ccc}
\hline & \multicolumn{3}{c}{ Average Earnings for One Subject } \\
Subject type & $2 / 3$-EXPERIENCED & $1 / 3$-EXPERIENCED \\
\hline Inexperienced & 6.45 & 6.97 \\
Experienced & 8.53 & 9.10 \\
$p$-value: & 0.048 & 0.075 \\
\hline
\end{tabular}




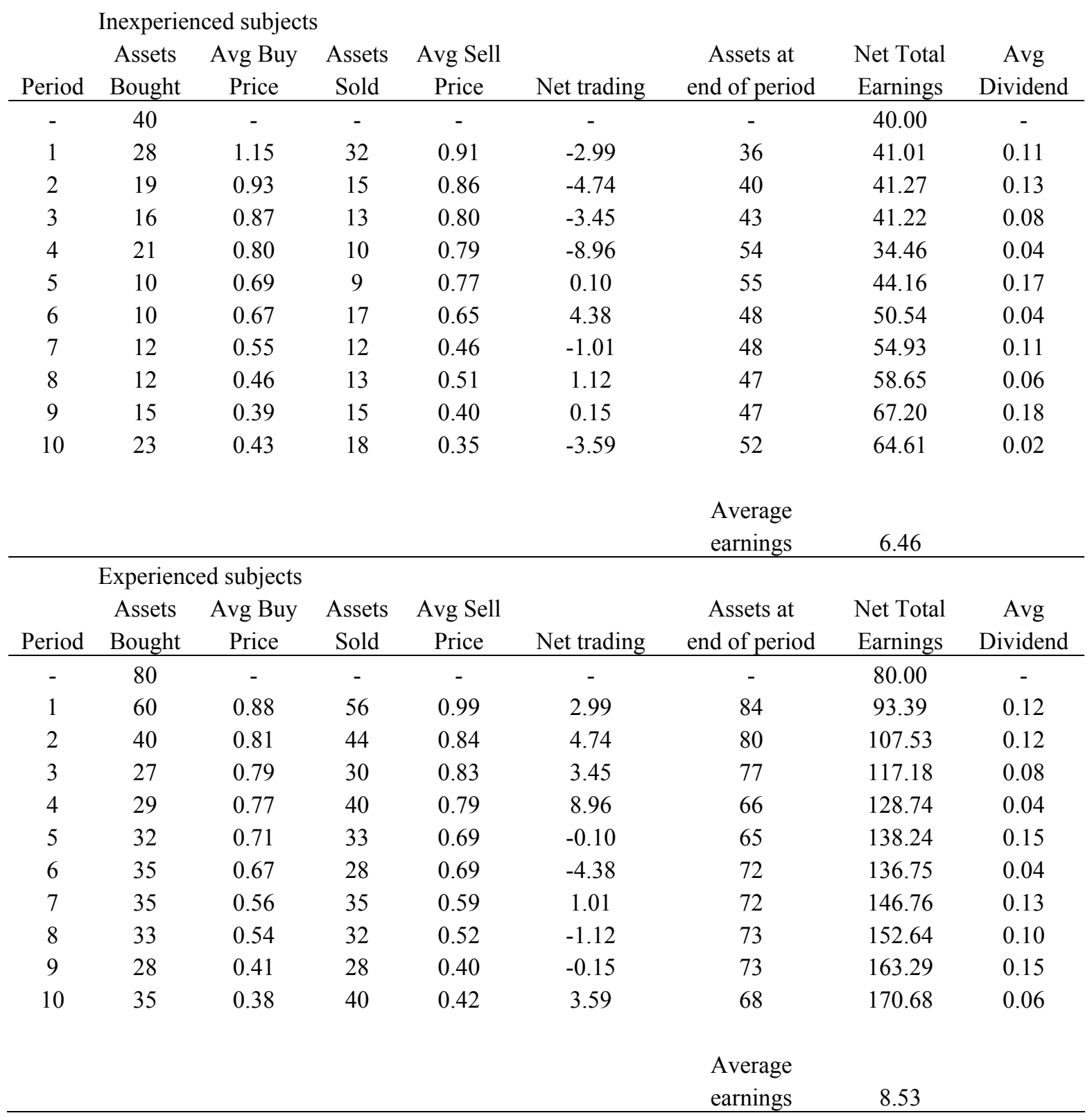




\begin{tabular}{|c|c|c|c|c|c|c|c|c|}
\hline \multirow[b]{2}{*}{ Period } & \multicolumn{2}{|c|}{ Inexperienced subjects } & \multirow[b]{2}{*}{$\begin{array}{c}\text { Assets } \\
\text { Sold }\end{array}$} & \multirow[b]{2}{*}{$\begin{array}{l}\text { Avg Sell } \\
\text { Price }\end{array}$} & \multirow[b]{2}{*}{ Net trading } & \multirow[b]{2}{*}{$\begin{array}{c}\text { Assets at } \\
\text { end of period }\end{array}$} & \multirow[b]{2}{*}{$\begin{array}{l}\text { Net Total } \\
\text { Earnings }\end{array}$} & \multirow[b]{2}{*}{$\begin{array}{c}\text { Avg } \\
\text { Dividend }\end{array}$} \\
\hline & $\begin{array}{l}\text { Assets } \\
\text { Bought }\end{array}$ & $\begin{array}{l}\text { Avg Buy } \\
\text { Price }\end{array}$ & & & & & & \\
\hline & 80 & - & - & - & - & - & 80.00 & - \\
\hline 1 & 78 & 0.77 & 75 & 0.70 & -8.00 & 83 & 74.80 & 0.03 \\
\hline 2 & 58 & 0.72 & 51 & 0.67 & -7.70 & 90 & 74.70 & 0.08 \\
\hline 3 & 43 & 0.64 & 43 & 0.56 & -3.50 & 90 & 82.20 & 0.12 \\
\hline 4 & 52 & 0.59 & 58 & 0.58 & 3.13 & 84 & 95.73 & 0.12 \\
\hline 5 & 42 & 0.58 & 39 & 0.59 & -2.50 & 87 & 99.83 & 0.08 \\
\hline 6 & 47 & 0.56 & 48 & 0.54 & -0.38 & 86 & 108.85 & 0.11 \\
\hline 7 & 39 & 0.52 & 37 & 0.52 & -0.85 & 88 & 111.60 & 0.04 \\
\hline 8 & 36 & 0.50 & 34 & 0.51 & -0.75 & 90 & 118.05 & 0.08 \\
\hline 9 & 50 & 0.50 & 43 & 0.52 & -2.61 & 97 & 127.84 & 0.13 \\
\hline \multirow[t]{2}{*}{10} & 46 & 0.32 & 49 & 0.33 & 1.16 & 94 & 139.40 & 0.11 \\
\hline & & & & & & $\begin{array}{l}\text { Average } \\
\text { earnings }\end{array}$ & 6.97 & \\
\hline \multicolumn{9}{|c|}{ Experienced subjects } \\
\hline Period & $\begin{array}{l}\text { Assets } \\
\text { Bought }\end{array}$ & $\begin{array}{l}\text { Avg Buy } \\
\text { Price }\end{array}$ & $\begin{array}{c}\text { Assets } \\
\text { Sold }\end{array}$ & $\begin{array}{c}\text { Avg Sell } \\
\text { Price }\end{array}$ & Net trading & $\begin{array}{c}\text { Assets at } \\
\text { end of period }\end{array}$ & $\begin{array}{l}\text { Net Total } \\
\text { Earnings }\end{array}$ & $\begin{array}{c}\text { Avg } \\
\text { Dividend }\end{array}$ \\
\hline & 40 & - & - & - & - & - & 40.00 & - \\
\hline 1 & 30 & 0.72 & 33 & 0.90 & 8.00 & 37 & 50.00 & 0.05 \\
\hline 2 & 21 & 0.77 & 28 & 0.85 & 7.70 & 30 & 59.70 & 0.07 \\
\hline 3 & 17 & 0.51 & 17 & 0.72 & 3.50 & 30 & 66.60 & 0.11 \\
\hline 4 & 19 & 0.63 & 13 & 0.68 & -3.12 & 36 & 67.48 & 0.11 \\
\hline 5 & 19 & 0.58 & 22 & 0.61 & 2.50 & 33 & 72.98 & 0.09 \\
\hline 6 & 18 & 0.53 & 17 & 0.58 & 0.38 & 34 & 78.36 & 0.15 \\
\hline 7 & 19 & 0.55 & 21 & 0.54 & 0.85 & 32 & 80.41 & 0.04 \\
\hline 8 & 12 & 0.53 & 14 & 0.51 & 0.75 & 30 & 83.56 & 0.08 \\
\hline 9 & 11 & 0.47 & 18 & 0.43 & 2.61 & 23 & 88.17 & 0.09 \\
\hline 10 & 16 & 0.32 & 13 & 0.31 & -1.16 & 26 & 91.01 & 0.15 \\
\hline & & & & & & $\begin{array}{l}\text { Average } \\
\text { earnings }\end{array}$ & 9.10 & \\
\hline
\end{tabular}

